\title{
7. IVAN ILITCH E WITTGENSTEIN: UMA ANALOGIA PRAGMÁTICA
}

\section{IVAN ILITCH E WITTGENSTEIN: A PRAGMATISTIC ANALOGY}

\section{Celso Augusto Nunes da Conceição ${ }^{1}$}

\begin{abstract}
Resumo: A leitura dualista de Ivan Ilitch a respeito do ser lógico e do ser sensível suscitou a analogia com os dois Wittgenstein: o primeiro e o segundo. A metodologia apresentada para isso parte da narração de Leon Tolstoi e a coteja com esses dois momentos da filosofia a partir dos aportes silogistas e contextuais. São muitas as inferências surgidas a cada confronto estabelecido, assim como argumentos baseados nos jogos da linguagem desse filósofo, que contrariou a sua teoria formalista a partir da aplicação das atividades linguísticas e não linguísticas fundamentadas nas relações contextuais. Essas duas ciências predominantes, Lógica e Pragmática, sustentam este artigo até o final, tanto na analogia como nas inferências provocadas no leitor.
\end{abstract}

Palavras-chave: silogismo, contexto, pragmática,

\begin{abstract}
The dual reading of Ivan Ilyich about to be logical and be sensitive raised the analogy the two Wittgenstein: the first and the second. The methodology presented to this starts with the story of Leo Tolstoy and compares these two moments of philosophy from silogists and contextual contributions. There are many inferences that arise to each established confrontation, as well as arguments based on the language games of this philosopher, who contradicted his formalist theory from the application of linguistic and non-linguistic activities based on contextual relationships. These two predominant sciences, Logic and Pragmatics, sustain this article until its end, not only at analogy but also regarding the inferences caused on the reading.
\end{abstract}

Keywords: syllogism, context, pragmatic

\section{Introdução}

Considerada novela ${ }^{2}$ pela grande maioria dos críticos da literatura universal, $A$ Morte de Ivan Ilitch, ${ }^{3}$ de Leon Tolstoi, é uma obra plurissignificativa e com nuances inferenciais que abrangem vários níveis do conhecimento humano.

\footnotetext{
${ }^{1}$ Professor das disciplinas de Português Jurídico e Direito e Linguagem no Cesuca, Mestre e Doutor em Linguística Aplicada na PUCRS. E-mail: celsus@terra.com.br .
} 
Particularmente, já na primeira leitura, o que mais me chamou a atenção foi o fato de que o protagonista Ivan Ilitch passa por dois momentos em sua vida: de um lado, a de um jurista formalista no sentido de buscar nos argumentos da lógica o seu porto seguro para se manter imparcial diantes das situações que envolviam o seu juízo, e por outro a sua relação com o meio familiar e social o impossibilitava de ser imparcial porque dependia das idiossincrasias do ser humano, notadamente os valores éticos e morais ${ }^{4}$.

Esse dualismo de Ilitch propiciou uma inferência analógica com um filósofo que, de certa forma, passou por esses dois momentos: Wittgenstein primeiro e segundo. Por que primeiro e segundo? O primeiro tem relação direta com a lógica, e o segundo com o mundo. Seu primeiro trabalho buscou os fundamentos da lógica e da linguagem através de muita reflexão porque entendia que era possível as pessoas entenderem por formalismos. Sem dúvida que, para chegar a outro momento, encontrou na linguagem princípios que o fizeram contrariar o seu próprio estudo.

Importante ressaltar neste artigo a pretensão de criar mais problemas do que os já tratados pela comunidade literária e científica. Para isso um possível paradoxo pode ser inferido pelos leitores: o de não ser formal apesar de apresentar a "formalidade" de Wittgenstein. Para esclarecer esse alerta, antecipo o caráter levemente transgressivo acerca do cientificismo acadêmico próprio dos artigos de revistas: algumas citações bibliográficas não serão referidas porque entendo serem indiferentes para o propósito deste $\operatorname{artigo~}^{5}$. E também porque a densidade de citações necessárias, em função das várias áreas envolvidas nesse processo, desfocaria o fio condutor da analogia dos dois personagens ${ }^{6}$.

A partir daqui, as seções serão divididas para contemplar o escopo do artigo: situações análogos para processos distintos, ou seja, excertos da obra associados às manifestações filosóficas.

\footnotetext{
${ }^{2}$ Esse termo é questionado por outros críticos que o consideram inadequado em função da quantidade de páginas que caracteriza a obra, destacando-a como conto por alguns e como romance por outros. Esta nota de rodapé é necessária para leitores específicos da área da literatura, como também àqueles que se interessam por questões semânticas que envolvem discussões em sentido geral.

${ }^{3}$ Não confundir com Ivan Illich, pensador e polímata austríaco (Viena, 04/09/1926; Bremen, 02/12/2002), que escreveu o livro "Sociedade sem escolas", editado pela Vozes, Petrópolis, 1985. A primeira edição é de1970 do título original em inglês: DESCHOOLING SOCIETY, da Harper \& Row, Publishers, Inc. Coincidentemente nasceu na mesma cidade de Wittgeinstein.

4 As definições de ética e moral serão desnecessárias em função do escopo deste artigo ser outro.

${ }^{5}$ Uma das pretensões deste artigo é fazer com que algumas notas de rodapé esclareçam o real intuito de determinadas afirmações. O porquê dessa observação será respondida por uma relação direta com uma afirmação de Wittgenstein a ser exposta.

${ }^{6}$ Entenda-se "personagem" como os dois protagonistas deste artigo: Ivan Ilitch e Wittgenstein.
} 
Revista Diálogos do Direito

http://ojs.cesuca.edu.br/index.php/dialogosdodireito/index

ISSN 2316-2112

Mas é oportuno destacar que a metodologia aplicada neste estudo já foi iniciada subliminarmente em dois parágrafos desta introdução. Segue-se com a linha condutora da relação da área da Lógica e da Pragmática sendo aplicada no cotejamento entre os dois personagens principais, Ilitch e Wittgenstein. E para manter a sequencialidade dessa condução, primeiramente uma breve definição dessas duas ciências linguísticas.

\section{Breves fundamentos da Lógica e da Pragmática}

\subsection{Lógica}

Em sentido geral, a Lógica é a ciência do pensamento e do raciocínio, estabelecendo estruturas formais capazes de gerar argumentos irrefutáveis. Chamado de "pai" dessa Lógica", Aristóteles foi o "construtor" desse método que revolucionou o novo pensar a partir do século I a.C. quando o filósofo grego peripatético Andrônico de Rodes reuniu suas obras, dando o nome de Órganon. Especificamente no Tópicos ${ }^{7}$, Aristóteles começa a definir o que é silogismo:

[...] Em primeiro lugar, vamos explicar o que é silogismo e quais são as suas variedades. Portanto, o objetivo desta pesquisa é entender o silogismo dialético.

Ora, o silogismo é um argumento no qual, estabelecidas certas coisas, outras coisas diferentes se deduzem necessariamente das primeiras. São elas:

(a) O silogismo é uma "demonstração" quando as premissas das quais ele parte são verdadeiras e primeiras, ou quando o conhecimento que delas temos provém originariamente de premissas primeiras e verdadeiras.

(b) O silogismo é "dialético" quando parte de opiniões geralmente aceitas. São "verdadeiras" e "primeiras" aquelas coisas nas quais acreditamos em virtude de nenhuma outra coisa que não seja elas próprias; pois, no tocante aos primeiros princípios da ciência, é descabido buscar mais além o porquê e as razões dos mesmos; cada um dos primeiros princípios deve impor a convicção da sua verdade em si mesmo e por si mesmo. São opiniões "geralmente aceitas" aquelas que todo mundo admite, ou a maioria das pessoas, ou os filósofos em outras palavras: todos, ou a maioria, ou os mais notáveis e eminentes.

[...] (ARISTÓTELES, 2013, p. 75/76)

A partir desse reduzido excerto ${ }^{8}$, já é possível fazer um atalho e apresentar a sua definição de silogismo ${ }^{9}$ proposicional estruturado (p. 188):

\footnotetext{
${ }^{7}$ Aristóteles, Poética e Tópicos I, II, III e IV. São Paulo: Hunter Books, 2013 (p. 75 a 76)

${ }^{8}$ Muitas páginas seriam necessárias para que todos os fundamentos fossem apresentados, mas podemos deixar aqui a sugestão para o leitor buscar um aprofundamento dos conceitos se assim o desejar.

${ }^{9}$ Silogismo, por definição, é um argumento válido; caso sua regra não seja bem aplicada, pode gerar sofismas ou falácias, constituindo-se assim em argumentos inválidos.
} 
Revista Diálogos do Direito

http://ojs.cesuca.edu.br/index.php/dialogosdodireito/index

\section{Cesuca}

ISSN 2316-2112

[...] é uma inferência (dedução) onde a verdade de uma proposição, isto é, sua conclusão, é uma consequência de duas outras proposições, as premissas. Um silogismo é estruturado da seguinte maneira: primeiro uma premissa maior, por exemplo "todo homem é mortal"; em seguida, uma premissa menor como "Sócrates é homem" e, por último, a conclusão: Sócrates é mortal".

E para ser mais específico, essa é a primeira regra, dentre várias, chamada de Modus Ponens (Modo Afirmativo), em que "a afirmação do termo antecedente (homem) conclui o seu consequente (mortal)". Dito de outra forma, o predicado da premissa menor (homem) advém da afirmação do sujeito (homem) da premissa maior, e o predicado da conclusão (mortal) advém do termo consequente da premissa maior (mortal).

O objetivo maior não é apresentar todo o "tratado" aristotélico, mas sim buscar a origem da Lógica para justificar o porquê Ilitch era considerado formalista, entendendo ele que a vida era lógica. Ele tinha como exemplo o silogismo da Lógica de Kiezewetter ${ }^{10}$ : "Caio é um homem, os homens são mortais, logo Caio é mortal". A propósito, esse silogismo está apresentado de forma correta? Pode-se fazer uma analogia com a estrutura silogista proposta por Aristóteles? Será que realmente Ilitch aprendeu lógica com esse exemplo? Tente responder a esses três questionamentos antes de seguir a leitura, identificando e explicando para alguém o possível problema apresentado na demonstração de ambos exemplos.

\subsection{Pragmática}

Inicialmente, assim como o nome do personagem na novela é praticamente homônimo de outro em função de alguns desatentos escreverem sobre ele e também porque a internet hoje permite a postagem de textos com algumas ${ }^{11}$ fontes não fidedignas, a palavra "pragmática" também pode provocar ambiguidades se não houver a devida contextualização. Por exemplo, é possível entendê-la com o significado de "regra ou conjunto de regras relacionadas com a prática social e jurídica, em oposição a palavras e fórmulas; praxe" ${ }^{, 12}$ ? E também por

"parte da teoria do uso linguístico que estuda os princípios de cooperação que atuam no relacionamento linguístico entre o falante e o ouvinte (p.ex.:

\footnotetext{
${ }^{10}$ Doutor e professor de Filosofia, Johann Gottfried Karl Christian Kiesewetter nasceu em 4 de novembro de1766, em Berlim, e faleceu no mesmo lugar em 19 de julho de 1819.

${ }^{11}$ Usei essa expressão como eufemismo, mas com certeza há muitas afirmações que carecem de veracidade; outras propositadamente falsas.

${ }^{12}$ Significado extraído do Houaiss (2009)
} 
Revista Diálogos do Direito http://ojs.cesuca.edu.br/index.php/dialogosdodireito/index

o enunciado você sabe que horas são? pode ser interpretado como um pedido de informação, como um convite a que alguém se retire etc.)"? (HOUAISS, 2009)

É possível uma palavra ter mais de um significado ou existe a coincidência da forma escrita? Minha conviç̧ão está nesta última. Tanto isso é verdade que o primeiro significado é de um termo da área jurídica; o outro, é da área linguística. Parece que ambos podem coexistir, mas em situações distintas.

Em relação ao presente artigo, é necessária a desambigualização para que a analogia fique consistente em seu propósito linguístico, mesmo que a indicação da obra $A$ morte de Ivan Ilitch esteja tenha sido objeto para a área jurídica.

Não foi ao acaso essa provocação inicial no que tange aos dois significados da palavra. Especificamente quanto à definição dessa ciência linguístico-filosófica, a ambiguidade é um dos problemas que afetam à Lógica porque dependem de contextos particulares e, às vezes, gerais para a sua eliminação. Como e por que surgiu?

A fim de evitar sobrecarga teórica, nomes como Charles Morris, Locke, Peirce, Carnap, Montague, Gazdar, entre outros, que foram os precursores do processo pragmático no sentido linguístico da palavra, somente são citados para posterior consulta aos fundamentos. Um salto seletivo com os teóricos Austin, Searle e Grice se faz necessário para a abordagem restritiva do processo comunicativo na relação linguagem e o homem, a Pragmática propriamente dita.

O inglês John L.Austin (1911 - 1960), um dos principais representantes da filosofia analítica, elaborou a teoria dos Atos de fala a partir de uma apurada análise da linguagem, em que faz uso de termos e expressões em seus contextos habituais de fala. Posteriormente, o filósofo John Searle (1932) desenvolve outros fatores enfatizando a intencionalidade no ato de fala.

Mas foi com Paul Grice (1975) que a Pragmática melhor se sistematizou. Ele estruturou o cálculo conversacional através do Princípio de Cooperação, em que há quatro máximas da conversação que são violadas para implicar algo, criando o termo implicatura para diferenciá-lo da implicação lógica. Dito de outra forma, é como se o interlocutor pedisse algo sem deixar explícito. O exemplo clássico é "Tens horas?" e o interlocutor responde as horas. Como é possível responder as horas se o que foi perguntado é se tinha? Pois é, Grice consegue essa proeza de formalizar os princípios que regem a comunicação 
Revista Diálogos do Direito

http://ojs.cesuca.edu.br/index.php/dialogosdodireito/index

humana através da intencionalidade: o falante perguntou ' $x$ ' querendo ' $y$ ', e o interlocutor entendeu a intenção e respondeu 'y'. E para se entender a "violação", o falante violou uma máxima da comunicação para implicar conversacionalmente: pediu ' $x$ ' querendo ' $y$ ' e o interlocutor "cooperou" entendendo a sua intenção e respondeu o que não foi dito, mas implicado.

Explicitando a sua teoria, tem-se o princípio cooperativo dividido nas quatro máximas:

Qualidade: Seja verdadeiro! Não diga algo que você acredita ser falso e não diga coisas para as quais você carece de evidências.

Quantidade: Diga o necessário! Não diga nada além e nem insuficiente.

Relevância: Seja relevante!

Modo: Seja claro, segundo quatro perspectivas

(i) Evite obscuridade

(ii) Evite ambiguidade

(iii) Seja breve

(iv) Seja ordenado

Por que relacionar a pragmática com o estado filosófico do segundo Wittgenstein? É possível essa relação? Aliás, por que primeiro e segundo para a mesma pessoa?

\section{O hibridismo dos dois Ilitch e dos dois Wittgenstein}

As duas seções a seguir apresentam o backgroud de cada um deles.

\section{a. Narração: autor e personagem em conflito}

Tolstoi é um narrador onisciente, aquele que sabe de toda história, conhece os seus personagens, podendo inclusive descrever seus sentimentos e saber como pensa cada um. A simultaneidade de fatos em locais diferentes é mais uma de suas características. Mas como ele é um narrador do tipo seletivo ${ }^{13}$, ele vai além: quando narra os fatos, se preocupa em relatar o que cada personagem pensa e quais as suas opiniões com a situação apresentada. Obviamente que influencia o leitor e o faz se posicionar a favor ou contra eles.

Isso tudo não seria problema se obra de Tolstoi tivesse unicidade de compreensão a respeito de quem está fazendo a observação, se o autor ou o personagem. Mas como tem,

\footnotetext{
${ }^{13} \mathrm{O}$ outro tipo é o neutro, aquele que faz observações somente para situar o leitor, não o influenciando no entendimento da narrativa.
} 
traz inquietações para quem lê porque em algumas situações seus comentários se hibridizam. Não consegui definir se a intenção dele era provocar esse tipo de confusão ou se ele não se deu conta do que produziu. Diante dessas considerações e como a proposta deste artigo está bem definida no título, considera-se opinião do personagem, Ivan Ilitch, cada vez que esse conflito acontecer. Com isso, eliminam-se determinadas inferências que poderiam, como já foi dito, desfocar o real objetivo deste ensaio literário-linguísticofilosófico. Questiono-me ${ }^{14}$ se essas inferências seriam suscitadas em todos os leitores? Acredito que dependeria de contextos específicos de cada um.

Por que Ilitch abandona a lógica? Aliás, será que abandona ou tenta conciliá-la com a sua situação de enfermo? Quem morreu, ele ou a lógica? Ou ambos?

\subsection{Filosofia: Wittgenstein em conflito}

Filósofo austríaco, Ludwig Wittgenstein (1889-1951) foi um grande estudioso da linguagem em sentido geral, minimizando-a aos aspectos puramente lógicos na sua primeira e única obra publicada em vida, entrando em conflito logo depois por entender de seu estudo carecia de uma investigação mais aprofundada.

\subsubsection{O primeiro escreveu Tractatus Logico-Philosophicus (TLP)}

Essa obra escrita por Wittgenstein foi o grande marco na história da filosofia, pois pretendia chegar à exaustão para os fundamentos da lógica e da linguagem. Escrita em menos de oitenta páginas, os aforismos categóricos foram os mais comentados na história do pensamento do século XX. A sua pretensão de traçar limites para a expressão do pensamento a partir do entendimento equivocado da lógica que era sustentada pelas formulações fillosóficas e metafísicas, resistiu até certo ponto. E fez incursões conceituais nas proposições aristotélicas, sentido e referência, valor de verdade, denotação e conotação, enfim, invejável material filosófico em somente uma obra. Mas em que ponto ele realmente se deu conta do problema? Acredito que foram várias afirmações que desconsideravam um único fato da linguagem. Para exemplificar, a sua afirmação no TLF (p. 9): “Tudo indica, portanto, que pensamento e sentido de uma proposição são a mesma coisa". Como a lógica é formal, reduzem tudo à mesma coisa, ou seja, os conceitos

14 Seria melhor "Me questiono", mas a gramática do Português Brasileiro ainda não permite a próclise ao verbo mesmo a comunidade brasileira tendo consagrado esse uso. 
desconsideram a relação das coisas com o significado, que é construído no diálogo entre as pessoas. Desconsideravam inclusive a própria ambiguidade na linguagem. Do que depende a ambiguidade para que possamos entende-la? Parece que a resposta a esse questionamento gera a inferência de que a solução passou por aí. Importante destacar os proeminentes nomes de Bertrand Russell e Gottob Frege nesse primeiro Wittgenstein.

3.2.2 O "segundo" contrariou o primeiro com as Investigações Filosóficas

Depois de ter concluído a sua obra, afastou-se dos seus estudos por aproximadamente oito anos. Nesse período nada de novo, mas retornou com outro olhar: crítica ao seu próprio trabalho, negando-o em suas conferências proferidas em Cambridge, onde era professor. Aproximadamente em 1929, segundo informações dos seus pares, é que aconteceu a sua "virada filosófica", criando assim uma filosofia de outro nível. Fazia seus apontamentos para a sua segunda obra chamada de Investigações filosóficas (IF), mas faleceu antes de sua publicação, o que aconteceu postumamente em 1945. Seus alunos reuniram suas anotações e posteriormente publicaram também.

Neste segundo momento, Wittgenstein dá-se conta que o significado não é mais estabelecido pela forma da proposição, quanto menos o sentido de seus componentes e a sua relação com os fatos. O ponto principal desse mudança começa com "o uso que fazemos das expressões . Mas isso não foi tão fácil assim para ele. Foi na sala de aula, através do método maiêutico de Sócrates, que propunha questões para os alunos responderem e a partir dessas respostas elaborava outras e assim ia construindo sua nova teoria.

As IF, parágrafo 43, apresenta de forma esclarecedora os jogos de linguagem, em que o significado da palavra está diretamente relacionado com o seu uso, mas é em um parágrafo anterior, o 23, que Wittgenstein explicita termos como "signo", "palavra", "frase" e outras tantos tipos de expressão de linguagem. Em suma reconhece que tanto o falante quanto ouvinte entendem a expressão pelo ambiente em que são produzidos.

\section{O cotejamento de ambos através dos excertos de suas obras}

Muitas são as passagens em cada obra que estabelecem certas inferências na relação dos personagens deste artigo, mas serão apresentados excertos para cada uma das situações 
de cotejamento, a saber: os dois são lógicos, a passagem do ser lógico para o ser social, e os dois seres sociais. Essa amostragem tem a precípua finalidade de mostrar como esse processo foi possível, desconsiderando todas as demais por não fazer sentido somente a corroboração de que essas analogias foram possíveis.

Para as referências às obras e Tolstoi e Wittgenstein, acrescento o uso de sigla MII, para A morte de Ivan Ilitch; TLP e IF já foram definidas anteriormente.

Na MII (p. 22), Ilitch deixa clara a impossilidade de fazer relação com o mundo, bastando seguir sua vida sem envolvimento com o meio, caracterizando-o como o primeiro Ilitch:

\begin{abstract}
Mas, de modo geral, a vida de Ivan Ilitch seguia seu curso como ele achava que deveria ser: calmamente, agradavelmente e dentro das normas estabelecidas, levantava às nove horas, tomava seu café, lia os jornais, vestia seu uniforme e ia para o Tribunal. Lá chegando, caía imediatamente na sua rotina de trabalho e preparava-se para lidar com petições, processos e as sessões públicas e administrativas. Em tudo isso, fazia-se necessário excluir dali tudo o que contivesse vida dentro de si - o que sempre perturba o andamento normal das coisas oficiais.
\end{abstract}

Da mesma forma, o primeiro Wittgenstein (TLP, pág. 9) apresenta seu raciocínio retirando da linguagem qualquer relação com o meio.

Tudo indica, portanto, que pensamento e sentido de uma proposição são a mesma coisa. O que há, porém, de ser a denotação inalterável que permanece nas duas proposições, na que tem como sujeito "a estrela da tarde" e na outra que tem como sujeito "a estrela da manhã"? O que é de comum a ambas é apenas o valor de verdade verdadeiro, de modo que não há outra que não há outra solução possível que senão tomá-lo como a denotação. Assim sendo, o pensamento é o sentido da proposição e um valor de verdade a sua denotação. Em lugar de referir-se aos fatos ou a uma conjunção de coisas, a proposição passa a denotar um objeto ideal constituído pelo valor verdadeiro ou pelo valor falso. (Sic)

A relação que os dois têm em comum é o fato de que o predomínio lógico é o que impera no pensamento de cada um: tudo é formalizado e estruturado previamente sem que haja qualquer influência do contexto em suas atividades.

A passagem do primeiro para o segundo, em relação a Ilitch, está no excerto da página 36 do MII. 
Revista Diálogos do Direito

Ivan Ilitch via que estava morrendo e desesperava-se. No fundo do coração sabia que estava indo embora e, longe de acostumar-se com a idéia, simplesmente não conseguia entendê-la. O exemplo de um silogismo que aprendera na Lógica de Kiezewetter, "Caio é um homem, os homens são mortais, logo Caio é mortal", parecera-lhe a vida toda muito lógico e natural se aplicado a Caio, mas certamente não quando aplicado a ele próprio. Que Caio, ser abstrato, fosse mortal estava absolutamente correto, mas ele não era Caio, nem um ser abstrato. Não: havia sido a vida toda um ser único, especial.

Nessa passagem, dentre outras, Ilitch entra em um conflito interior em função de que o "sujeito" Caio da proposição silogista é um ser abstrato que não tem nenhum vínculo com as relações sociais. Ele era o seu guia em todas as manifestações enquanto jurista no Tribunal. Não se deixava abater por nenhuma influência sentimental ou de outra natureza. As relações dele com as pessoas não passavam de pura formalidade para que continuassem a exercer suas atividades para as quais fora determinado. Quando chegava em casa, conseguia não se deixar abater com sentimentos, e se algum fato novo o fazia pensar diferente, aplicava o pragmatismo social: adequava-se ao meio refugiando-se em seu escritório particular. Mas qual foi o motivo que o fez mudar essa conduta? O que aconteceu para entrar em conflito existencial? Por que renegou a relação que tinha com o personagem do silogismo? Devagar, mas a Pragmática já está presente por aqui através de seu contexto, pano de fundo para as relações intencionais nos atos de fala. Mas como tratar dos atos de fala se ele está falando com ele mesmo? Bem, ele está refletindo com o seu eu. Isso não caracterizaria a relação do falante e ouvinte?

Quanto ao Wittgenstein (IF, p. 7-8), o excerto na apresentação de sua obra

As linguagens perfeitamente ordenadas são transparentes e como que eternas . Ideais e imutáveis, são, contudo, desprovidas de vida e de morte, e insensíveis para as diferenças históricas e a diversidade cultural da humanidade. A linguagem real da vida não considera apenas as estruturas lógicas que se podem ordenar com perfeição e transparência. A linguagem real da vida se mantém sempre em aberto e abrindo-se para usos sempre novos e jogos em contínua reformulação. A fonte da vida histórica dos homens é o caos, no sentido originário da palavra grega. Trata-se de uma experiência inaugural tão rica e dinâmica que dela se origina tudo que é e nela se nutre toda criação em qualquer área ou nível do real e/ ou possível, do necessário e/ ou contingente. 
deixa a passagem de um para o outro muita clara, pois retoma a afirmação do seu TLP, em que as linguagens são extremamente transparentes e ordenadas, não sofrendo nenhuma interferência da vida ou da morte, ou seja, é atemporal e imutável. Mas posteriormente a isso, o segundo Wittgenstein já assume a linguagem como algo real, considerando as estruturas lógicas e ao mesmo tempo a intervenção do homem com o meio, dependente da linguagem para a comunicação. E são os jogos de linguagem o objeto principal de sua teoria. Por quê? Essa expressão deixa clara a noção de que a mutabilidade ocorre em função das alterações na relação falante/ouvinte? Aqui a Pragmática já entra como pressuposto das relações de linguagem através de seu contexto e intencionalidade.

Por último, a presença dos "segundos" nos dos excertos do MII e IF. Primeiramente no MII (p. 26-28), o segundo Ilitch reflete sobre as afirmações do médico:

O médico disse-lhe que este e aquele sintoma indicavam que isto ou aquilo iam mal com o paciente por dentro, mas se esse diagnóstico não fosse confirmado pelos exames clínicos disto ou daquilo, então chegaremos a esta ou aquela conclusão. Se chegarmos a esta ou aquela conclusão, então... e assim por diante. Para Ivan Ilitch só importava saber uma coisa: o seu caso era sério ou não era? Mas o médico ignorou essa pergunta tão fora de propósito. Do ponto de vista do médico tratava-se de um detalhe que não merecia ser levado em consideração: o problema realmente era avaliar todas as probabilidades e decidir entre um rim flutuante ou apendicite.

$[\ldots]$

- Nós, os doentes, sem dúvida fazemos muitas vezes perguntas inadequadas. Mas, diga-me, de modo geral, assim por cima, esses sintomas lhe parecem graves ou não? O médico olhou-o severamente por cima do monóculo, como se dissesse: "Pedimos ao réu que se atenha a responder o que lhe foi perguntado ou serei obrigado a fazer com que o retirem da sala".

Como se sabe, a doença de Ilitch pode ter sido provocada pela batida que deu no corrimão da escada. Isso é uma inferência autorizada, mas não garantida porque o Ivan morreu sem saber qual foi a causa de sua morte. Foram muitos os diálogos em que ele deixa claro que não acredita nas pessoas e nem no médico. Tem certeza de que todos estão mentindo, ou seja, estão produzindo afirmações falsas.

No primeiro parágrafo do excerto, há um diálogo implícito uma vez que o narrador é onisciente e se permite não explicitá-los. Pragmaticamente, no sentido linguístico da palavra, quando Ilitch pergunta se é grave e o médico desconversa, está havendo aí uma 
violação da máxima de quantidade porque respondeu sem responder, ou seja, a sua ignorada gerou a inferência de que não queria responder por algum motivo, para Ilitch, mas para o narrador está claro que entendeu a pergunta como inapropriada. Mas Ivan entendeu a intenção do médico e logo em seguida fez a pergunta que garantia que a inferência era autorizada. Nova pergunta e nova ignorada, desta vez com um olhar que disparava proposições. E esta inferência é oportuna para este estudo porque retrata o seu conflito existencial: ele queria a atenção do médico, mas comparou a sua maneira de responder com a sua atitude enquanto jurista. Fez ilações bem pertinentes, questionando a sua própria conduta de um formalista que não se envolvia com os réus. Está neste momento sentindo o que os réus também sentiam: tudo pelas regras, sem envolvimento emocional algum.

Pelo excerto da página 239 do IF, o cotejamento do exemplo de Wittgenstein é muito oportuno para o propósito deste artigo porque ele pretende uma coisa, mas permite duas:

\begin{abstract}
O médico pergunta: "Como é que ele se sente?"
A enfermeira diz: "Está gemendo."

Um relato sobre o comportamento.Mas é preciso, afinal, que exista a pergunta para ambos: se este gemer é realmente autêntico, se é realmente expressão de alguma coisa? Eles não poderiam, p. ex., tirar a conclusão."Se ele está gemendo, temos que dar-lhe um medicamento que tire a dor" - sem omitir um termo médio? O que importa não é o serviço de que eles colocam a descrição do comportamento?

"Mas então eles fazem uma pressuposição tácita ". Então o processo do nosso jogo de linguagem repousa sempre sobre uma pressuposição tácita
\end{abstract}

É possível perceber que nas investigações Wittgenstein, mesmo utilizando diálogo como exemplo, a fim de inferir um silogismo, já esboça um conteúdo pragmático griceano. Vejamos, o falante (médico) pergunta à enfermeira "Como é que ele se sente?"; a interlocutora (enfermeira) responde: "Está gemendo.". Ela respondeu à pergunta do médico? Ela não respondeu explicitamente como ele se sente, violando um princípio de cooperação da máxima de quantidade para implicar conversacionalmente que "ele precisa de medicamento". Na verdade, a enfermeira disparou uma implicatura conversacional e o médico a capturou, a inferência. E agora, projetando esse exemplo no diálogo de Ivan Ilitch, tem-se inferências diversas. É possível garantir que o produtor da pergunta ou da resposta gerou inferência facilmente entendidas pelo interlocutor? "Facilmente" é uma palavra eufemística nesse caso. Teorica e praticamente, as inferências pragmáticas podem 
ser todas canceladas porque a intencionalidade é do falante e ele pode negá-las porque a intencionalidade é bem particular pois depende de contextos específicos. Tudo isso e mais ainda estão no TLP de Wittgenstein.

\section{Considerações finais}

O insights aparecem geralmente quando fazemos relações de algo com outro. E não foi diferente nesse artigo que se propôs a apresentar uma analogia entre dois personagens, um fictício e outro real. O primeiro, produto da ficção baseado, por inferência, na vida de seu autor-narrador; e o outro um indivíduo real que reflete o mundo para encontrar o link que une o homem à sua linguagem.

Tentei, especialmente neste artigo, evitar o tecnicismo acadêmico, que tanto prima pelas fontes, mas que impede de certa forma uma redação mais livre e mais fluente em sua leitura. Alguém pode questionar: "Mas como posso confiar no que está escrito se não há fonte?". Bem, sem a pretensão wittgensteiniana quanto ao "porque me é indiferente que alguém mais já tenha, antes de mim, pensado o que pensei”, arrisquei, de certa maneira, fazer uma experiência com o público leitor a respeito da omissão de algumas fontes, acreditando que o conteúdo do artigo não seja prejudicado. E para autores que foram citados no trabalho, sem essa especificação e por se tratar de nomes reconhecidamente universais, o leitor pode corroborar a ausência bibliográfica não sentida quando o propósito não diz respeito diretamente ao trabalho em questão, mas que foi indicado como tangenciamento teórico. Certamente essa minha convicção poderá gerar problema em função de as regras já estarem estabelecidas. Mas será que é possível existirem duas tipos de regras para a execução de um mesmo propósito, assim como há múltiplas linguagens?

Dentre os entendimentos gerados a partir da plurissignificação deste artigo, é possível inferir que os dois Ilitch morreram? Ou só morreu o segundo porque o formalismo lógico é intocável com as suas premissas desvinculadas da realidade do mundo? E à Wittgenstein, arrisco a inferência de que o segundo matou o primeiro, metaforicamente, é claro, estendendo essa relação ao segundo Ilitch, que morreu com a certeza de que o primeiro, o lógico, não morreu porque a lógica não tem relação com a vida.

Quanto ao TLP e também às IF, o material denso, mas que lido com paciência e atenção estimula o leitor a fazer como Wittgenstein: estudar sempre para criar a partir do que já está definido como pronto.

Diante de todas considerações, acrescento que eu não esperava entrar em um emaranhado linguístico-filosófico desse nível. Mesmo tendo planejado o escopo desse estudo, deparei-me com uma "ida sem volta", em que parecia, e ainda está parecendo, um 
Revista Diálogos do Direito

http://ojs.cesuca.edu.br/index.php/dialogosdodireito/index

caminho movediço que inebria o indivíduo a cada passo dado. Fico com a certeza de que esse assunto não se esgota nesta última frase, mas sim que ela é o estímulo para uma longa caminhada pelos jardins das áreas da linguagem.

\section{REFERÊNCIAS BIBLIOGRÁFICAS}

ARISTÓTELES. Poética e Tópicos I, II, III e IV. São Paulo: Hunter Books, 2013.

HOUAISS ELETRÔNICO. Dicionário Houaiss da Língua Portuguesa. Rio de Janeiro: Editora Objetiva, 2009.

LEVINSON, Stephen C. Pragmática. Trad. de José Arthur Giannotti. São Paulo: Martins Fontes, 2007.

TOLSTOI, Leon. A morte de Ivan Ilitch. Trad. Vera Karam. Porto Alegre: L\&PM, 2002.

WITTGENSTEIN, Ludwig. Tractatus Logico-Philosophicus. Trad. José Arthur Giannotti. São Paulo: Editora Universidade de São Paulo, 1968. . Investigações filosóficas. Trad. Marcos G. Montagnoli. Petrópolis: Vozes, 2009.

(Artigo submetido em 01/12/2014 e aceito em 28/12/2014) 